\title{
O EFEITO DA SUBSTITUIÇÃO TRIBUTÁRIA DO ICMS QUE INCIDE SOBRE A PESSOA JURÍDICA
}

\section{ARTIGO DE REVISÃO}

COSTA, Keno Gleison Moraes da ${ }^{1}$

BARROSO, Kelson de Almeida ${ }^{2}$

COSTA, Keno Gleison Moraes da. BARROSO, Kelson de Almeida. O efeito da substituição tributária do ICMS que incide sobre a Pessoa Jurídica. Revista Científica Multidisciplinar Núcleo do Conhecimento. Ano 05, Ed. 01, Vol. 02, pp. 0513. Janeiro de 2020. ISSN: 2448-0959, Link de acesso: https://www.nucleodoconhecimento.com.br/contabilidade/substituicao$\underline{\text { tributaria }}$

\section{RESUMO}

O regime de substituição tributária (ST) é um meio de quota determinado pela Constituição Federal de 1988. Ele prove a contenção de modo antecipado do ICMS, sendo retirado ainda na primeira etapa do processo ou serviço que um produto percorre até o consumidor final. Esse processo é considerado como uma manobra do Estado para mitigar a sonegação de impostos e promover, efetivamente, o controle dos contribuintes. O objetivo principal será compreender seus conceitos e refletir sobre os efeitos da Substituição Tributária na administração financeira da pessoa jurídica, pois, para o governo, esta manobra é considerada benéfica às empresas, sobretudo na realização do recolhimento unificado dos impostos e na redução do tributo declarado, visto que os produtos liberados pelas fábricas e importadores já

\footnotetext{
${ }^{1}$ Graduando em Ciências Contábeis pela Faculdade La Salle.

${ }^{2}$ Graduação em Licenciatura Plena em Matemática pelo Centro Universitário de Ensino Superior do Amazonas (2003); Mestrado em Economia pela UCB (2012) e Doutorado em Economia pela UCB (2019).
} 
saem com suas devidas taxas. A metodologia norteadora foi baseada na revisão bibliográfica, e, dessa forma, contou-se com livros, artigos, revistas e sites oficiais, de modo a promover e evidenciar os aspectos relevantes para a compreensão e reflexão desta temática para fins acadêmicos bem como recorreu-se a outros materiais que possuem interesse nos impactos causados por essa ST destinada à pessoa jurídica. Conclui-se que a substituição tributária existe em todas os impostos importantes do encargo social, considerando sua relevância tanto para os órgãos arrecadadores quanto para a nossa sociedade.

Palavras-chave: Substituição Tributária, ICMS, imposto.

\section{INTRODUÇÃO}

Sabe-se que o ICMS é um dos principais impostos cobrados pelo Brasil, sendo ele um imposto colocado sobre a circulação de mercadorias, a prestação de serviços de transporte intermunicipal e interestadual e sobre a comunicação. Possui competência estadual e, assim, cada estado é responsável por sua tributação e cada um institui suas regras. É um imposto considerado complexo e de grande ocorrência, cujos órgãos competentes encontram dificuldades para fiscalizar todos os seus contribuintes. A criação da substituição tributária teve como objetivo diminuir a sonegação de tributos, de acordo o Art. 150 §7, que prevê que havendo a necessidade da sistemática ST, deve se estender aos outros diferentes produtos que tiveram que ser tributados como substituídos do ICMS. Tem como alicerce o convênio do ICMS 81/93 que detém as diretrizes gerais aplicadas na ST e estabelece a obrigatoriedade da emissão de nota fiscal para a compensação do tributo.

Assim, cada Estado deverá realizar consultas na legislação da substituição para cada destino atrelado à mercadoria. Tal recolhimento é retido logo na primeira etapa do processo ou serviço como forma de diminuir a omissão de tributos e ter maior índice na arrecadação dos tributos. Segundo Santos (2017), para que toda essa sistemática tributária funcione de modo efetivo é importante haver a fixação de um preço de venda, que, por sua vez, é estabelecido pela legislação tributária. Esse preço de venda será definido como base para o cálculo da ST. Ela também servirá para a obtenção do valor 
final do produto repassado para o consumidor final. A ST aparece na Constituição Federal de 1988, na Lei Complementar ㄲo 87/1996, na Lei ㄲo 1.254/1996, no regulamento 18.955/1997, no Convênio ICMS 81/93 bem como nos demais convênios e protocolos aprovados pelo CONFAZ.

A substituição tributária tem sido um assunto bem presente nas agendas dos governantes e das grandes empresas do setor privado. Parece ser inevitável esta modalidade de recolhimento, uma vez que atinge os ramos de atividades voltados à fabricação de cigarros, sorvetes, pneus, distribuidoras de gasolinas e seus derivados assim como nas empresas que constroem autopeças automotivas. De modo algum, segundo Brasil (1996), o Art.155 prevê que o ICMS deverá ser na forma cumulativa, ou seja, as entradas do tributo pago nas entradas dos produtos geram crédito ao fisco e débitos fiscais na sua saída, e, desse modo, o ICMS será cobrado a cada etapa da cadeia produtiva de uma mercadoria ou serviço. O imposto é o repasse de quantia em dinheiro paga para o sustento do governo federal, dos estados e dos municípios. $O$ pagamento é feito tanto por pessoas físicas quanto jurídicas.

É um tributo que serve para custear parte das despesas derivadas do setor da administração bem como diz respeito, também, aos investimentos do governo em obras de infraestrutura e serviços essenciais à população. Desse modo, o artigo tem como objetivo principal compreender seus conceitos e refletir sobre os efeitos da Substituição Tributária na administração financeira da pessoa jurídica. A metodologia será norteada por uma revisão bibliográfica pautada em livros, artigos, revistas e sites oficiais, de modo a promover e evidenciar os aspectos relevantes para a compreensão e reflexão desta temática para fins acadêmicos assim como recorreu-se a outros autores que possuem interesse nos impactos causados por essa ST destinada à pessoa jurídica. Nesse sentido, o estudo serve como base para outras propostas de pesquisa. 


\section{REVISÃO DE LITERATURA}

\subsection{TRIBUTO}

Tributo é uma contribuição de valor monetário, paga em moeda corrente. Tem como promotora a lei e exclusivamente advém de uma situação licita, sendo a sua cobrança requerida por um dos entes governamentais (MAFFINI, 2017). De acordo com o Código Tributário Nacional - CTN, Art. 3: define-se como tributo "toda prestação pecuniária compulsória, em moeda ou cujo valor nela se possa exprimir, que não constitua sanção de ato ilícito, instituída em lei, e cobrada mediante atividade administrativa plenamente vinculada" (BRASIL, 1966, p. 1). Para melhor compreensão sobre os conceitos de tributos é preciso analisar, de forma separada e detalhada, essa definição.

De acordo com Oliveira et al (2010) ,a prestação pecuniária é referente ao tributo pago em moeda corrente, já o compulsório é uma obrigação que está além da vontade do contribuinte, uma vez que, em moeda, encontram-se os impostos apresentados em moeda corrente (reais) e indexados na forma de (OTN, BTN, Ufir) que não tenha penalidade de ato ilícito, instituído, para isso, em lei, assim, deve haver uma norma jurídica com força de lei para requerer tal obrigação. A prestação cobrada, por sua vez, é feita por meio de uma atividade administrativa íntegra vinculada da qual a lei já define todos os passos a serem realizados deixando, então, a autoridade sem escolha quanto ao melhor tempo para cobrar o tributo. Existem três finalidades para os tributos: a fiscal, extrafiscal e a parafiscal.

Segundo Maffini (2017), a finalidade fiscal serve, apenas, como forma de embolsar recursos para apoio do Estado bem como para custear as suas ações, havendo, dessa forma, a transição do contribuinte para os cofres públicos. Os impostos ficais possuem a intenção apenas de receber, provendo, então, de recursos o Estado. A finalidade extrafiscal exerce influência direta nos impostos sobre produto ou mercadoria e tem por finalidade regular o mercado ou a economia de um determinado lugar. Já o parafiscal tem como objetivo o recebimento dos recursos para patrocinar as atividades que não fazem parte das funções do Estado. Tributos diretos são aqueles das quais 
a contribuição é promovida pelo próprio contribuinte, ou seja, é quando uma única pessoa atribui a condição de contribuinte, e, assim, há a realização de todos os ônus tributários dispostos na legislação.

Já os tributos indiretos são aqueles que estão ligados ao ordenamento jurídicotributário. Devido a esse caráter, é determinado pelo Estado. Enquadra-se como um sujeito passivo, e, desse modo, paga os ônus e acaba recuperando bem como repassa, a terceiros, a inclusão do imposto no preço (ALMEIDA, 2013). Segundo o Código Tributário Nacional (CTN) os tributos recebem classificações como impostos, taxas e contribuição de melhoria. Dentre esses, os impostos são vistos como os mais relevantes, recaindo, então, sobre o contribuinte, independente da sua posição. A taxa é um tributo mais difícil, pois ela tem como fator gerador o serviço público de forma própria e fragmentada. A contribuição de melhoria, por fim, é o menos conhecido, cobrado, apenas, pela União, Estados e DF e Municípios (BRASIL, 1966).

\subsubsection{OBRIGAÇÃO TRIBUTÁRIA}

De acordo com o princípio legal do Código Tributário Nacional - Lei № 5.172/66, a obrigação tributária tem relação jurídica com o Estado, tendo o fisco o direito de requerer do contribuinte uma parcela. Ela pode ser dividida em dois modos: pode ser compreendida como uma obrigação principal e como uma obrigação acessória. Desse modo, a obrigação principal é o embolso do tributo em si, somado a multas e juros, caso os tenha. Ela é uma obrigação proveniente do fator gerador que tem como objetivo o embolso do tributo ou penalidade pecuniária. Já a obrigação acessória pode ser qualquer obrigação da qual a lei tributária venha a exigir do contribuinte, sendo caracterizada a partir de normas formais, como emissão de nota fiscal e outros tipos de registros (MAFFINI, 2017).

\subsection{ASPECTOS GERAIS DO ICMS}

O ICMS substituiu o antigo IVC - Imposto sobre Vendas e Consignações, que atuava no aumento da sua aplicação. Assim, atingia produtos em geral e recaía sobre todas as etapas de produção, efeito este conhecido como "cascata" (MARCHETTI, 2016). 
O Imposto sobre Circulação de Mercadorias e Serviços - ICMS é um imposto de competência dos Estados e do Distrito Federal. Tem como fator gerador operações como a circulação de mercadorias, serviços de transportes interestadual e intermunicipal e os serviços de telecomunicações. Está previsto na Constituição Federal de 1988, no Art. 155 e regulamentado pela Lei oo 87 de 1996 (BRASIL, 1996). Desse modo, somente os governos estaduais podem interferir ou alterá-lo. Nessa perspectiva, o objetivo do ICMS é apenas fiscal, e, assim, o promotor gerador é, justamente, a circulação das mercadorias. Até mesmo aquelas que tem início no exterior sofrem este tributo.

Para Denari (2002), a ocorrência do ICMS não acomete, apenas, as mercadorias, mas também as prestações de serviços que estão envolvidas com o transporte interestadual e municipal e com as comunicações. Ele é um tributo indireto, e, assim, não possui parâmetros diretos para validar a capacidade econômica do contribuinte, diferente do imposto direto que é cobrado conforme a capacidade de contribuição do contribuinte, como, por exemplo, o IR. Poderá ser atribuído a posto de substituto tributário a qualquer contribuinte ou depositário, de acordo com a lei estadual. A lei complementar de № 87/1996 regulamenta a norma da constituição, cabendo, a ela, a definição dos fatos e parâmetros centrais da sistemática da cobrança. Contudo, é preciso que haja a supervisão desses créditos com o objetivo de reduzir e aprimorar, legalmente, o ICMS a ser pago (BENÍCIO, 2010; ALMEIDA, 2013).

\subsection{SUBSTITUIÇÃO TRIBUTÁRIA DO ICMS}

A Constituição Federal destina a competência de regulamentar o ICMS aos Estados e ao Distrito Federal. Eles devem seguir as diretrizes normatizadoras da lei complementar de № 87/1996, conhecida como a Lei de Kandir. O ICMS recai sobre todas as etapas da cadeia de produção, acarretando em um efeito cascata até chegar ao consumidor final, que também fica sujeito a tributação (MENDONÇA et al., 2017). Segundo Bortolon (2011), o ICMS tem como característica a seletividade, a atuação indireta e a não cumulatividade. Entretanto, a seletividade está ligada a necessidade dos produtos e serviços, ou seja, aos produtos de grande necessidade, como, por exemplo, os alimentícios. Eles são tributados com quotas inferiores e contam com 
relações mercadológicas fúteis. No entanto, para Oliveira et al (2015), a não cumulatividade acaba por beneficiar o contribuinte em crédito. Isso ocorre sempre que ele obter um produto ou serviço já com o imposto aplicado, e, assim, será abatido quando o mesmo obter o registro de uma saída ou venda.

Nesse contexto, a sistemática da substituição tributária do ICMS para o recolhimento do ICMS diverge pelo simples fator da legislação estadual e do federal acabar delegando a uma pessoa que participa da cadeia de produção a responsabilidade do recolhimento do imposto. Por exemplo, o fabricante se responsabiliza em relação ao atacadista e ao varejista, já o atacadista e o varejista se responsabilizam pelo consumidor final (ALMEIDA, 2013). De acordo com a lei complementar de № 87/1996 há três tipos de substituição tributária que se distinguem nos seus critérios de aplicabilidade. São elas as operações antecedentes, operações concomitantes e operações subsequentes (BRASIL, 1996). As operações antecedentes são denominadas como uma substituição regressiva ou para trás e estão atreladas aos atos geradores que ocorrem anteriormente, ou seja, o contribuinte que participa da cadeia circulatória pagará o imposto após o fator gerador já ter ocorrido (ALMEIDA, 2013). As operações concomitantes são aquelas executadas por um outro contribuinte.

Não pode ser o mesmo que efetua a operação ou serviço. Para Benício (2010), esta forma de ST é aquela em que a quitação do débito é realizada quando se origina a obrigação por uma pessoa diferente do contribuinte. As operações agregadas a atos geradores futuros, são substituições para a frente (operações subsequentes) e são as mais aplicadas pelos Estado e o DF no diz respeito a arrecadação do ICMS. A lei agrega a responsabilidade do imposto incidente a um dos contribuintes localizados no início, destacando-se os produtos dos bens ou os seus distribuidores primários (BENÍCIO, 2010; OLIVEIRA, 2015). O convênio ICMS de № 2/2015 determina como deverá ser o sistema de uniformização e identificação dos produtos e bens aptos aos regimes de ST do ICMS com o desfecho dos tributos sobre as operações progressivas. Este ICMS está relacionado aos prazos determinados nas legislações 
de cada estado, nos convênios e nos protocolos que tratam da ST com tempo determinado para os produtos da qual deles fazem parte (CONFAZ, 2015).

\section{CONSIDERAÇÕES FINAIS}

O ICMS é o tributo relativo à Circulação de Mercadorias e, também, incide sobre as Prestações de Serviços de Transporte Interestadual e Intermunicipal e de Comunicação. Cabe aos Estados e ao Distrito Federal a competência de estabelecer e cobrar o ICMS. Essas entidades fazem com que o contribuinte se torne responsável pelo recolhimento do tributo. É por meio da ST do ICMS que se detém o tributo das operações subsequentes antecipado ou das operações com consentimento posterior. É uma manobra usada pelo Estado para viabilizar a fiscalização dos contribuintes, o que implica, diretamente, na mitigação das fraudes relativas aos impostos, pois os produtos já saem de suas linhas de produção ou do importador tributados. Percebese que essa manobra beneficia o governo, entretanto, em relação à pessoa física, essa manobra de cobrança tem causado grandes interrogativas.

Estão entre os principais questionamentos relacionados a inserção de obrigações acessórias e também ao aumento da obrigação principal. Nesse contexto, de acordo com Santos (2017), para viabilizar a sua administração, o governo elaborou a ST, que é o primeiro substituto tributário da cadeia de produção. Assim sendo, a prestação ou operação na área de concentração do tributo para cada etapa da cadeia de produção acaba sendo requisitado de modo antecipado para o substituto tributário, de onde origina-se o fator gerador e o objeto da operação. Podemos, também, concluir que se uma empresa possui fundos de tempo reduzido, sendo eles sua reserva de capital, eleva-se, então, sua segurança quando o saldo é positivo ou terá que custear parte da privação do capital de giro, também denominado ativo permanente com fundos de prazos limitado, quando o saldo for negativo.

Ainda neste contexto, pode-se concluir que tal fator impacta, diretamente, na descapitalização do caixa, implicando na saúde monetária da empresa, pois o pagamento antecipado acaba reduzindo o saldo de caixa e acaba exigindo que a empresa reduza a sua privação do capital de giro ou que invista mais dinheiro no 
capital de giro. Esses fatos devem ser avaliados pela administração financeira da empresa para que ela não seja acometida ao processo de falência pela falta de capital para pagar seus compromissos devido a uma má conduta na administração financeira associada a substituição tributária. Ressalta-se que o estudo buscou apresentar uma reflexão relativa aos efeitos da substituição tributária do ICMS que incide sobre a pessoa jurídica de maneira geral. Entretanto, tais observações também servem como sugestões para futuras pesquisas, pois pode-se, ainda, incluir outros enquadramentos tributários ou regimes específicos além de, também, promover outras formas para minimizar a tributação imposta às mercadorias.

\section{REFERÊNCIAS}

ALMEIDA, C. A. de. O impacto da substituição tributária do ICMS no capital de giro das empresas. Revista Científica Semana Acadêmica, v. 1, n. 43, p. 1-15, 2013.

BENÍCIO, S. G. ICMS: apontamentos teóricos e práticos sobre a substituição tributária. São Paulo: Saraiva, 2010.

BRASIL. Constituição (1988). Constituição da República Federativa do Brasil. Diário Oficial [da] República Federativa do Brasil, Brasília, DF, 5 out. 1988. Disponível em: http://www.planalto.gov.br/ccivil_03/constituicao/constituicaocompilado.htm. Acesso em: 25 set. 2019.

BRASIL. Lei complementar no 87, de setembro de 1996, 1996. Disponível em: http://www.fazenda.gov.br/confaz/confaz/diversos/lc_087.htm. Acesso em: 24 set. 2019.

BRASIL. Lei no 5.172, de 25 de outubro de 1966, 1966 Disponível em: http://www.planalto.gov.br/ccivil_03/leis//5172.htm. Acesso em: 22 set. 2019.

BORTOLON, B. R. Impactos da Substituição Tributária do ICMS sobre a carga tributária das empresas optantes pelo Simples Nacional: um estudo multicasos em duas empresas de Santa Catarina. 2011. Disponível em: http://tcc.bu.ufsc.br/Contabeis295848.pdf. Acesso em: 24 set. 2019. 
CONFAZ. MINISTERIO DA FAZENDA. Convênio ICMS 81/93. Disponível em: https://www.confaz. fazenda.gov.br/legislacao/convenios/1993/cv081_93. Acesso em: 22 set. 2019.

CONFAZ, MF - CONVÊNIO ICMS 92, de 20 de Agosto de 2015. Disponível em: https://www.confaz.fazenda.gov.br/legislacao/convenios/2015/convenios-icms-92-15. Acesso em: 25 set. 2019.

DENARI, Z. Curso de direito tributário. São Paulo: Atlas, 2002.

DODF. Ministério da Fazenda - DF. Anexo IV ao Decreto no 18.955, de 22 dezembro de 1997. Disponível em:

http://www.fazenda.df.gov.br/aplicacoes/legislacao/legislacao

TTelaSaidaDocumento.cfm?txtNumero $=18955 \&$ txtAno $=1997 \& t x t$ Tipo $=6 \&$ txtParte $=A N$ EXO\%2004\%20CADERNO\%2001. Acesso em: 18 set. 2019.

DODF. Ministério da Fazenda - DF. Lei n 1.254, de 8 de Nov. de 1996. Disponível em: http://www.fazenda.df.gov.br/aplicacoes/legislacao/legislacao/TelaSaidaDocume ntocfm?txtNumero $=1254 \&$ txtAno $=1996 \& t x t T i p o=5 \& t x t P a r t e=$. Acesso em: 28 set. 2019.

MAFFINI, O. K. Substituição tributária nas esferas municipal, estadual e federal: tributos - ISSQN, ICMS, IPI, PIS/PASEP, COFINS, CSLL e INSS. 2017. $91 \mathrm{f}$. Monografia (Especialização em Ciências Contábeis) - Universidade Federal de Mato Grosso, Cuiabá, 2017.

MARCHETTI, L. Z. O impacto do ICMS na substituição tributária em uma indústria optante pelo simples nacional. 2016. 94 f. TCC (Graduação em Ciências Contábeis) - Universidade Federal Fluminense, Volta Redonda, 2016.

MENDONÇA, F. M. de. et al. O impacto do ICMS por substituição tributária na liquidez e rentabilidade das empresas do setor metalúrgico: estudo de caso. In: Anais do Congresso de Administração, Sociedade e Inovação - CASI 2016. Anais...Juiz de Fora (MG) UFJF, 2017. 
OLIVEIRA, L. M. et al. Manual de Contabilidade Tributária. 14 ed. São Paulo: Atlas. 2015.

OLIVEIRA, L. M. et al. Manual de Contabilidade Tributária. 9 ed. São Paulo: Atlas. 2010.

SANTOS, A. M. dos. Substituição Tributária ICMS. Revista Eletrônica Cosmopolita em Ação, v. 4, n. 1, p. 13-27, 2017.

Enviado: Novembro, 2019.

Aprovado: Janeiro, 2020. 